rev.relac.int.estrateg.segur.11(1):103-119,2016

\title{
¿ESTADOS FALLIDOS? O SOBRE LA IMPOSIBILIDAD DE CONSTITUIR EL ESTADO NACIÓN MODERNO*
}

\author{
Flabián Nievas ${ }^{* *}$ \\ Carolina Sampó***
}

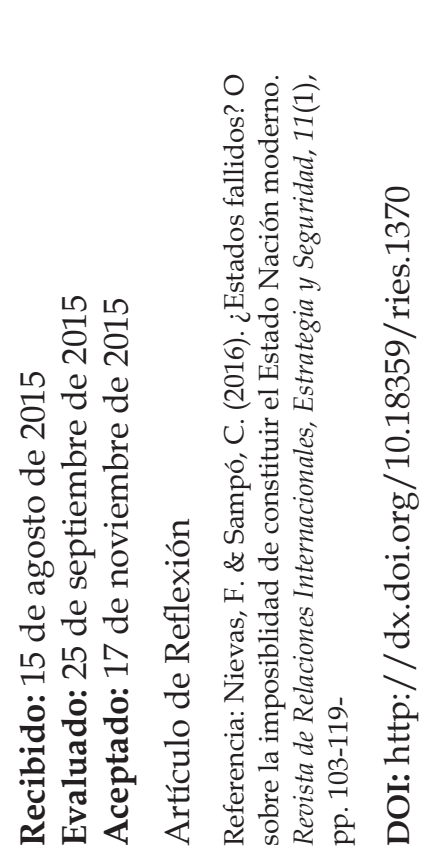

\section{RESUMEN}

Existe cierto consenso en que la existencia de Estados Fallidos genera inestabilidad en el Sistema Internacional, ya que los mismos parecen facilitar el asentamiento de organizaciones criminales trasnacionales que se valen de sus territorios para desarrollar y potenciar sus negocios. Sin embargo, la inclusión de un sinnúmero de casos en esta categoría fuerza una revisión no sólo del concepto sino también de la idea

* El presente artículo se inscribe en el proyecto UBACyT Código: 20020130100717 BA denominado "Guerra, Estado y Teoría Social" a desarrollarse entre los años 2014 y 2017. Parte de la discusión conceptual sobre los Estados Fallidos proviene de la tesis de Carolina Sampó "El impacto de los Estados en Proceso de Falla en la Seguridad regional: El caso de Paraguay en el Cono Sur" presentada en la Universidad Torcuato Di Tella para obtener el título de magister en Estudios Internacionales.

** Doctor en Ciencias Sociales por la Universidad de Buenos Aires (UBA) y Licenciado en Sociología (UBA). Es Profesor titular en la UBA e investigador independiente de CONICET. flabian.nievas@gmail.com

*** Doctora en Ciencias Sociales por la Universidad de Buenos Aires, Magister en Estudios Internacionales por la Universidad Torcuato Di Tella y Licenciada en Ciencia Política (UBA). Es docente en la UBA y en la Universidad Nacional de La Matanza (UNLAM). carosampo@gmail.com 
que existe detrás del mismo, anclada en la concepción de Estado-Nación moderno. De allí que el objetivo del presente trabajo es discutir el alcance del concepto de Estado Fallido, teniendo en cuenta que el Estado Nación moderno ha encontrado fuertes dificultades para su consolidación en distintos lugares del planeta. Durante la investigación nos preguntamos si es posible vincular de forma inseparable al Estado y a la nación o si deben tratarse como conceptos separados que en algunos casos se encuentran juntos. En esa misma línea: ¿Son los Estados los que fallan o es la construcción del Estado-nación la que nunca se concretó? ¿Cuál es el papel del reconocimiento internacional del Estado en este tipo de conceptualizaciones?

Palabras claves: Estados Fallidos, Estado Nación, Legitimidad, Seguridad Internacional

\title{
FAILED STATES? OR THE IMPOSSIBILITY TO CONSTITUTE THE MODERN NATION-STATE
}

\begin{abstract}
There is some consensus that the existence of Failed States generates instability in the international system since they appear to facilitate the settlement of transnational criminal organizations that use their territories to develop and increase their business. However, the inclusion of many different cases in this category force a review not only of the concept but also of the idea that lays behind it, the conception of modern nation-state. Hence the objective of this paper is to discuss the scope of the concept of failed state, considering that the modern nation state has found strong difficulties for its consolidation in many parts of the world. During the research we ask ourselves if it is possible to link inseparably the State and the nation or whether they should be treated as separate concepts that are sometimes together. In the same line: Are the states the ones that fail or is the construction of the nation-state which has never materialized? What is the role of international recognition of the state in this kind of conceptualization?
\end{abstract}

Keywords: Failed States, Nation State, Legitimacy, International Security

\section{ESTADOS-FALHADOS? O SOBRE A IMPOSIBILIDADE DE CONSTITUIR O ESTADO- NAÇÃO MODERNO}

\section{RESUMO}

Há certo consenso de que a existência de Estados falidos tem gerado estabilidade no sistema internacional, uma vez que eles aparecem para facilitar a criação de organizações criminosas transnacionais que usam seus territórios para desenvolver e aprimorar seus negócios. No entanto, a inclusion de um número de casos nesta categoria força uma avaliação não só do conceito mas também de a idéia de que há por trás disso, ancorada na concepção de Estadonação moderno. Por isso, o objetivo deste trabalho é discutir o alcance do conceito de Estado Falido, considerando que o Estado-nação moderno tem emcontrado sérias dificuldades para 
sua consolidação em diferentes partes do mundo. Durante a pesquisa nos perguntamos se é possível conectar inseparavelmente o Estado da nação ou se devem ser tratados como conceitos distintos que estam em alguns casos juntos. Na mesma linha: Os estados estão falhando ou a construção do Estado-nação que nunca se materializou? Qual é o papel do reconhecimento internacional do Estado em tais concepções?

Palavras-chaves: Estado Falido, Estado Nação, Legtimidade, Segurança Internacional

\section{INTRODUCCIÓN}

El concepto de Estado Fallido es una idea contemporánea que da cuenta básicamente de las problemáticas, deficiencias e imposibilidad de ciertos Estados para responder a las diversas demandas que hacen sus ciudadanos. (Zapata, 2014, p. 89)

Convencionalmente se acepta que la seguridad internacional descansa en parte, tal como apunta Rotberg (2002), en la capacidad de los gobiernos nacionales de evitar el caos interno y limitar el efecto que la existencia del mismo pueda tener más allá de sus fronteras, situación que no garantizan, o lo hacen muy débilmente, los denominados "Estados fallidos"; que son unidades políticas con reconocimiento internacional, incapaces de cumplir con las funciones básicas atribuidas al Estado-nación moderno. Esta idea, comúnmente aceptada, contiene tres supuestos discutibles: la noción de seguridad, la de cómo se designa un Estado "fallido", y la de qué es lo que falla en los mismos. Aunque discutiremos los tres supuestos mencionados, nos centraremos en el tercero, proponiendo otro enfoque para entender qué es lo que falla en los denominados "Estados fallidos".

Con este fin, el documento se divide en cinco partes. En primer lugar, la presente introducción que además de presentar el trabajo profundizará en las diferencias conceptuales existentes entre Estados fallidos, anómicos y débiles. Segundo, nos concentraremos en la idea de Estado que rige en el mundo actual y buscaremos explicar a qué hacemos referencia cuando mencionamos al Estado-nación moderno. En ese mismo apartado discutiremos los fundamentos de la legitimidad estatal y el rol de la idea de nación en la construcción del Estado moderno. En cuarto lugar, analizaremos algunos casos en los que es la nación la que parece fallar, más que el Estado y, finalmente, en las conclusiones plantearemos la necesidad de pensar al Estado desde otro lugar.

\section{Sobre la adjetivación de los Estados}

Si por seguridad internacional se entiende la ausencia de conflictos bélicos interestatales, cumplimiento de la normativa internacional y respeto por otros Estados en sus políticas internas, 
no puede decirse que cualquiera de los clasificados como Estados fallidos sean los que ponen en mayor medida en peligro la misma. Muy por el contrario, los Estados que en el último medio siglo han participado de mayor cantidad de contiendas bélicas allende sus fronteras son Estados Unidos, Gran Bretaña y Francia. Resulta Ilamativo que se indique a este tipo de Estados con un papel preponderante en la seguridad internacional cuando el mayor problema de los mismos es interno, y carecen de capacidad de agresión. La presunta utilización de su territorio por parte de organizaciones criminales no parece ser mayor a la que estas organizaciones hacen de otros territorios.

Como sostiene Alda Mejias (2015) son los Estados débiles, no los fallidos, los que presentan mejores condiciones para el desarrollo de la criminalidad organizada. Los Estados fallidos, en cambio, se hallan inmersos en el caos interno no pudiendo garantizar la protección ni de los ciudadanos ni del crimen organizado. Por el contrario, el desorden y la extrema debilidad característica de este tipo de Estados puede poner en riesgo los negocios de las redes criminales y la protección que precisan para sobrevivir y reproducirse.

La evidencia indica que la mayor actividad criminal se asienta en países con mayor capacidad de consumo y bienestar; la criminalidad de la pobreza no atrae a las grandes organizaciones, y los Estados fallidos suelen carecer de la infraestructura básica para la criminalidad altamente organizada que precisa, entre otras cosas, una extendida red bancaria en la cual lavar el dinero (significativamente, ni los "paraísos fiscales" están en la lista de los Estados "fallidos", ni éste es un criterio para la clasificación de los mismos). De allí la transnacionalidad de las organizaciones criminales y su construcción de redes, como resultado de lo segmentadas que se encuentran sus actividades.

Esa omisión, traslada la atención del concepto a las fuentes que lo producen. Pese a ser un concepto ampliamente difundido en la Ciencia Política y las Relaciones Internacionales, el mismo no proviene de la academia sino de agencias gubernamentales, paragubernamentales como "think tanks" u organismos multilaterales, las principales de las cuales son la organización para la cooperación y el desarrollo económico (OCDE), Fund for Peace, la revista Foreign Policy, la Agencia de los Estados Unidos para el Desarrollo Internacional (USAID), el Departamento de Desarrollo Internacional del Reino Unido, el Banco Mundial y la Agencia Central de Inteligencia (CIA) (Gutiérrez, 2010; Alonso, 2003). Estos son los organismos que elaboran los principales índices de Estados fallidos. Como menciona Woodward (2006), la literatura sobre este tipo de Estados asume la existencia de un modelo normativo de Estado (liberal-democrático, amigable con el mercado, transparente, que rinde cuentas sobre su accionar y cuenta con ciertos requerimientos institucionales). Es razonable suponer, por lo tanto, que se trata más de un concepto político-operativo que de una categoría académica.

No obstante, eso no elude la realidad de que hay Estados-nación que o bien han colapsado, o bien están en problemas que los acercan al punto de colapso, es decir, en un proceso por el cual el Estado se debilita paulatina pero constantemente y reduce tanto su capacidad de control, 
como su legitimidad frente a la sociedad civil. Estos debilitamientos pueden ser analizados a la luz de los atributos que debe alcanzar un Estado para ser considerado como tal, a saber: capacidad para internalizar y externalizar su poder (ser reconocido como la única autoridad legítima dentro y fuera de su territorio), capacidad de internalizar el control y diversificar su autoridad, y capacidad para internalizar una identidad colectiva, es decir, crear o consolidar una nación (Oszlak, 1982). Claramente, la incapacidad de los Estados de alcanzar o sostener uno o algunos de los atributos mencionados hace que el mismo se encuentre en proceso de falla, puesto que no ha logrado imponerse ni en su territorio ni frente a sus habitantes ni tampoco ha sido reconocido internacionalmente.

De acuerdo con Chester Crocker (2003) el proceso de falla de los Estados es gradual y está intrínsecamente relacionado con el desarrollo de conflictos internos y crisis humanitarias. Dicho proceso, puede expandirse desde un área o una zona específica del Estado hasta hacer colapsar la estructura estatal por completo, generando un efecto desestabilizador sobre los Estados vecinos. Es por eso que, si bien es importante distinguir entre Estados Débiles, Anómicos y Fallidos esta categorización puede ser entendida como la secuencia por la que pasa un mismo Estado antes de colapsar. De cualquier forma, hay que destacar que este proceso no es lineal y que muchos Estados débiles pueden permanecer dentro de esa categoría por largos periodos, sin necesariamente convertirse en Estados anómicos o fallidos.

De acuerdo a lo expuesto por Peter Waldmann (2003), la debilidad estructural de un Estado se materializa en la incapacidad del mismo de garantizar un orden pacifico vinculante para todos sus ciudadanos. Un Estado débil, aparece como una entidad que:

no ha podido imponerse en los aspectos centrales de la soberanía -monopolio de la recaudación impositiva y de la fuerza- frente a los grupos de la sociedad y los individuos que le disputan este derecho. Por otro lado, nunca ha conseguido refrenar ni disciplinar a sus propios miembros y órganos, siendo esto en parte la consecuencia y la causa de lo mencionado antes. (Waldmann, 2003, p.15)

Algunos autores agregan a esto la incapacidad o falla que los Estados débiles muestran a la hora de: crear un ambiente que conduzca a un crecimiento económico equitativo y sustentable, establecer y mantener instituciones políticas legítimas y transparentes y preservar a la población de conflictos violentos, al tiempo que proveen las necesidades básicas a su población (Rice \& Patrick, 2008)

Un Estado hoy débil institucionalmente, señala Waldmann, nunca logró convertirse en un fin en sí mismo, sino que se presentó siempre como un instrumento para la implementación de diversos fines impulsados por las elites. De ahí se derivan dos características centrales de este tipo de Estados: el carácter burocrático del Estado es limitado o prácticamente inexistente; y, el Estado es una red clientelística que distribuye privilegios entre quienes forman parte del poder, así como a aquellos que los rodean. Este último elemento dificulta la modificación 
o reformulación de la estructura estatal para su posterior fortalecimiento, considerando que cualquiera de estas políticas sería contraria a los intereses de quienes ocupan el poder.

La debilidad institucional del Estado termina por generar una brecha -difícil de sortear- entre las elites políticas y la sociedad civil, que al no ver garantizadas sus necesidades básicas se niega a legitimar la estructura. Dicha brecha, posibilita la existencia y legitimación de organizaciones no estatales capaces de proveer los bienes comunes que el Estado no consigue garantizar. Es decir, que los Estados débiles generan incentivos para el asentamiento de organizaciones criminales transnacionales por la estructura misma sobre la que se hayan establecidos. Es importante destacar, que este tipo de Estados cuenta con mecanismos que permitirían el ejercicio efectivo de la soberanía interna e interdependiente ${ }^{1}$ pero que se han visto debilitados, sea por la profundización del proceso de globalización o sea por los intereses detentados por las elites dominantes. En muchos casos, es la falta de recursos principalmente económicos la que impide el ejercicio efectivo de la soberanía.

A diferencia de un Estado débil, tal como señala el mismo Waldmann, un Estado anómico cuenta con cuatro características particulares (2003):

1. El Estado no ofrece a sus ciudadanos un marco de orden para su comportamiento en el ámbito público, puesto que no crea certezas en cuanto al comportamiento y la orientación de la sociedad civil.

2. El Estado pretende regular ámbitos sociales y modos de comportamiento que ocupa de forma ficticia y no está en condiciones de controlar o dominar efectivamente.

3. El propio personal del Estado no cumple con las leyes, convirtiéndose en un foco de arbitrariedad y desviación de normas.

4. El Estado carece de la legitimación fundamental por parte de sus ciudadanos puesto que no logra satisfacer las necesidades básicas respecto del mantenimiento del orden y la seguridad. En este escenario, sin orden no hay reconocimiento ni de la estructura, ni de la autoridad estatal.

La debilidad institucional del Estado -específicamente referida a la estructura interna del aparato estatal- es un aspecto a ser tenido en cuenta a la hora de definir un Estado anómico, pero no el único. Es pero eso que dichos conceptos no deben ser considerados equivalentes, sino que deben ser utilizados de forma diferenciada.

1. La soberanía interna está referida a la organización formal de la autoridad política dentro del Estado y su capacidad de ejercer un control efectivo dentro de las fronteras del mismo; mientras que la Soberanía Interdependiente se refiere a la capacidad de control que poseen las autoridades públicas a la hora de regular los distintos flujos que traspasan sus fronteras (Krasner, 2001) 
Los Estados anómicos cuentan, además, con porciones territoriales significativas que se encuentran en manos de organizaciones paralelas - "zonas grises"- donde el Estado no tiene capacidad para ejercer la soberanía interna, al igual que en ciertas zonas de frontera donde no puede ejercer efectivamente la soberanía interdependiente.

Como resalta Alda Mejias (2015) la diferencia entre Estados Fallidos y débiles (nosotros agregamos a los anómicos) es una cuestión de grado. En el caso de los primeros, es "la situación más próxima al incumplimiento integral de la legalidad y en consecuencia a la anomia absoluta".

En contraposición con los dos tipos de Estado antes mencionados, los Estados fallidos carecen de la capacidad de ejercer ningún tipo de control sobre la soberanía interna e interdependiente (Krasner, 2001).

Siguiendo a Zapata Callejas (2014) vemos como muchos autores han trabajado sobre la definición de Estados fallido y, aunque difieren en aspectos teóricos, casi todos coinciden en que las condiciones que denotan la existencia de un Estado fallido son: la pérdida del monopolio de la fuerza, expresada en la ineficacia en prestar seguridad tanto externa como interna, la incapacidad para prestar servicios básicos a sus ciudadanos, altos grados de corrupción e inestabilidad institucional, crisis económicas, deficiencias jurídicas y luchas culturales, entre otras.

Es interesante mencionar, como lo hace Zapata Callejas (2014), que de acuerdo con Jean Marie Grose existen cinco tipos de Estados fallidos demostrando la heterogeneidad de los casos: aquellos en donde no hay poder político centralizado; allí donde solo hay una autoridad limitada de Estado; Estados con escasos recursos en guerra con grupos secesionistas; Estados que están manejados por grupos étnicos; $y$, territorios donde no hay un poder único que posea el monopolio de la fuerza.

Afganistán, Iraq y Somalia, entre otros, dejan de manifiesto la inexistencia misma de un Estado nación moderno, o bien porque éste nunca se ha podido construir o bien porque el mismo ha colapsado como consecuencia de conflictos de diverso origen o bien porque reconocen organizaciones políticas alternativas. Demuestran, además, que existen en el planeta un gran número de matices que hacen que las categorías comúnmente utilizadas resulten insufiencientes.

\section{¿De qué hablamos cuando hablamos de Estado?}

Uno de los problemas centrales que se plantea en esta discusión es mucho más profunda que la mera adjetivación del Estado y refiere al alcance mismo del concepto. Sin duda, cuando hablamos de Estados en proceso de falla definimos, casi naturalmente, a la unidad política como un Estadonación moderno. Pero ¿es posible vincular de forma inseparable al Estado y a la nación o deben tratarse como conceptos separados que en algunos casos se encuentran juntos, pero que en muchos no logran conformarse como un todo? ¿Son los Estados los que fallan o es la construcción 
de la nación la que nunca se concretó? ¿Cuál es el papel del reconocimiento internacional del Estado en donde aparece lo que Robert Jackson denomina Cuasi-Estados (Berrio, 2003)?

Los casos que aparecen como recurrentemente mencionados al hablar de Estados fallidos parecen mostrar que el Estado-nación no habría logrado conformarse. Somalia, Afganistán, Irak y hasta Haití son una muestra de ello. De ahí que sea necesario preguntarse si lo que falla no es la construcción de nación, más que el Estado como forma de organización política (aunque en estos casos existen formas de organización paralelas que incluso demuestran que es posible alcanzar el orden más allá de las fronteras conceptuales). Deberíamos comenzar por analizar la díada Estado-nación, que es problemática, ya que "nación" es una noción imprecisa. Hobsbawm se preguntaba:

¿Qué es una nación (o la nación)? Porque la característica principal de esta forma de clasificar a los grupos de seres humanos es que, a pesar de que los que pertenecen a ella dicen que en cierto modo es básica y fundamental para la existencia social de sus miembros, o incluso para su identificación individual, no es posible descubrir ningún criterio satisfactorio que permita decidir cuál de las numerosas colectividades humanas debería etiquetarse de esta manera. (2012, p. 13)

Incluso Gellner, en su estudio ya clásico propone dos criterios provisionales, imprecisos e insuficientes: cierta unidad cultural y el reconocimiento de sus miembros de la pertenencia a la misma (1991). ¿De dónde surge, entonces, la necesidad de asociar un aparato político (el Estado) con algo tan vago como la "nación"? Ésta es, en nuestra opinión, la cuestión fundamental.

El Estado-nación surge, como concepto y fácticamente, a partir del relativo agotamiento del último modelo estatal medieval, el Estado absolutista (Anderson, 2005), corroído por la expansión de las relaciones mercantiles en las que se asentaba. Esta contradicción inmanente (que sustentó la utopía pacifista de Adam Smith y de Inmanuel Kant) se tornó irreversiblemente inviable cuando a las tensiones propias se le sumaron las religiosas. La conjunción de todo ello dio lugar a un conjunto de conflictos armados que se conocen en su totalidad como "guerra de los Treinta Años" (1618-1648), que culminó con los tratados de paz de Osnabrück y Münster, en los que se sentaron los principios sobre los que se edificó el sistema interestatal moderno, sistema que creó, conjuntamente, las unidades que lo conforman. El Estado-nación es consecuencia de este ordenamiento fundado en la soberanía estatal, por contraposición a la soberanía del monarca, y a la integridad territorial, en oposición a la práctica (y concepción) hereditaria de pueblos y territorios cuya contigüidad era contingente y su unidad, inexistente.

Estos Estados, de acuerdo con Boege, Brown, Clements \& Nolan (2008), tienen un papel dual: una función externa, consistente en servir como unidad básica para el sistema internacional $y$, una función interna, que consiste en proveer seguridad y establecer el orden interno en beneficio de los ciudadanos. Dicho orden, en el Estado Nación moderno, se encuentra 
íntimamente vinculado a la construcción de una identidad colectiva en la que se expresa la nación. El problema, en realidad, radica en que muchos de los países que se encuentran fuera de la Organización para la Cooperación y el Desarrollo Económico (OCDE) son entidades políticas que se parecen muy poco al modelo occidental popularizado por el Estado Liberal. Esos Estados, nuevos en su mayoría (resultantes de los procesos de descolonización que tuvieron lugar en la segunda mitad del siglo XX), "carecían de raíces en el seno de las sociedades sobre las cuales se pretendía construir, esencialmente en aquellos casos donde no existió ningún tipo de gobierno unitario pre-colonial" (Boege, Brown, Clements \& Nolan, 2008, p.11). Pero más allá de la debilidad sobre la que se erigieron, es importante tener en cuenta el impacto que la dinámica del sistema global ha tenido sobre la estatalidad. En muchos casos, la influencia externa ha afectado negativamente la legitimidad (como por ejemplo, la implementación de las medidas del llamado Consenso de Washington).

Este nuevo trazado dio lugar a un ordenamiento más estable, pero carente de la legitimidad consuetudinaria y/o divina del orden feudal. Esta falta de legitimidad se expresa en la publicación de Leviatán, o la materia, forma y poder de una república eclesiástica y civil, en 1651, un intento de justificación del Estado absoluto (no debe confundirse con absolutista) basado en el contrato social, es decir, mudando la soberanía de lo divino a lo terrenal ${ }^{2}$. Lo distintivo de Hobbes es que "enuncia la doctrina según la cual la persona jurídica que yace en el corazón de la política no es ni la persona del pueblo ni la persona oficial del soberano, sino más bien la persona artificial del estado" (Skinner, 2003, p.101). Ese Leviathan que todo veía, todo sabía y todo controlaba, era resultado de los intereses de todos los ciudadanos, quienes habían resignado sus derechos naturales en favor de la seguridad. El derecho a no sufrir una muerte violenta fue para Hobbes, el argumento central para la conformación de un Estado absoluto.

Esa mutación expresaba el profundo cambio que suponía la emergencia del capitalismo como sistema dominante en Europa, que reordenaba socialmente los espacios, y requería de una correspondencia en el reordenamiento político del territorio, funcional a su dinámica.

\section{La cuestión nacional y la legitimidad estatal}

La rápida expansión de la forma de Estado-nación por casi toda la superficie firme del planeta merece una explicación, particularmente cuando se constata que es una forma que en nada se adecúa a las organizaciones sociales preexistentes en muchos espacios donde esta forma estatal se ha implantado. Tilly (1993) llama la atención sobre la peculiaridad de la forma Estadonación, e investiga el proceso histórico en que el mismo fue imponiéndose a otras formas estatales (imperios, ciudades-Estado, entre otros). Es necesario advertir, no obstante, que la forma estatal moderna resulta funcional al sistema capitalista y, por lo tanto, en la medida en

2. "Como el poder del Estado es omnipotente, tiene carácter divino. Pero su omnipotencia es de origen muy distinto, es obra humana, y nace por virtud de un 'contrato' que celebran los hombres". (Schmitt, 2002, pp. 31-32). 
que éste se expande y consolida, se expandió la forma del Estado-nación, incluso allí donde era totalmente extraño a las tradiciones políticas.

Ahora bien, la forma estatal, en tanto aparato jurídico-político necesita de legitimidad para sostenerse en el tiempo; la mayoría de la población debe reconocer la potestad gubernamental de disponer de la organización estatal y de la regulación de las actividades sociales. En las formas feudales (incluso en las absolutistas, la última de estas formas), así como en las formas clánicas y tribales, el poder se corporiza en una persona que por sus cualidades extraordinarias (origen divino, sabiduría, riqueza, poder militar, etc., a menudo varias de ellas combinadas) es identificable y venerada. Cuando los Estados se despersonalizan (en parte, efecto Westfalia, aunque el proceso es más amplio y complejo) se pierden estas referencias vitales de legitimidad ${ }^{3}$. En este sentido, Calatrava \& Durán (2011) sostienen que la legitimidad del Estado se justifica a través de tres narrativas: la seguridad, que hace referencia al acuerdo a la hora de crear el orden; la representación, puesta en marcha a partir del contrato social a partir del cual se intercambian límites a la libertad por el acceso al orden civil; y el bienestar, asegurado por el acceso a la propiedad y el mercado. Asimismo, los autores consideran que otra forma de obtener legitimidad es a partir del suministro de bienes públicos que abarcan cuestiones intangibles y difíciles de cuantificar como la educación, las instituciones y las obras de infraestructura. No obstante, estas consideraciones - generalmente aceptadas - no contradicen nuestra observación; las tres narrativas referidas, y más aún la legitimidad "por beneficio" (obtención de bienes y servicios públicos), son formas de legitimidad de segundo orden, ya que parten del supuesto de una aceptación inicial, o de primer orden, del orden político legitimado. En esta primera instancia es donde inscribimos el proceso de formación de las naciones.

En ese contexto la revolución francesa marcó un hito insoslayable, al infundir un nuevo concepto de "nación" (ahora asociado al Estado) con la expansiva energía revolucionaria que se difundió por gran parte de Occidente. Hasta entonces, el concepto de "nación" era asimilable al de "pueblo", ${ }^{4}$ sin que tal noción se refiriera a territorios definidos (el caso más significativo era sin dudas el de la nación hebrea, pero también otras naciones: magiares, rutenos, polacos, moravios, alemanes, etc.). A partir de ese momento, quedó indeleblemente ligado al aparato estatal. De tal modo, aquellos pueblos que aspiraban a conformar un Estado propio se reclamaban como naciones, a la vez que allí donde se formaban Estados, éste tenía como primera y primordial tarea, formar la nación. Pero la misma se organiza en forma de mito, no hay bases objetivas preexistentes (religión, lengua, costumbres o lo que fuere) ${ }^{5}$. La formación y solidificación del

3. Hasta el gran sacudimiento europeo de 1789, la expresión 'legitimidad' no admitía plural, había una sola legitimidad, la dinástica. A partir de la Revolución, se produce el eclipse de la vieja legitimidad tradicional y el alumbramiento de otras nuevas, como la nacional-revolucionaria de los jacobinos y la carismática del Primer Cónsul. (Bandieri, en Schmitt, 2007, p. 9)

4. Incluso actualmente se mantiene parcialmente ese significado en la idea de "autodeterminación de los pueblos" (Rosdolsky 1980, p.136).

5. Esto es así incluso en los casos alemán e italiano. En ellos: 
mito resultó, en general, exitosa. Pero no en todos los casos fue así. Donde esto no ocurrió, el Estado, en el corto o mediano plazo, al carecer de legitimidad, se demostró inviable.

Una de las cuestiones centrales radica en que, de acuerdo con Boege, Brown, Clements \& Nolan (2008), las instituciones estatales reclaman autoridad dentro de un espacio territorial en el que sólo se encuentran algunos avances de la estatalidad. Como el Estado no impregnó a la sociedad en su conjunto, el control efectivo del Estado no pudo extenderse sobre ella. Sin embargo, aun cuando las instituciones estatales no estén presentes en gran parte del territorio eso no implica que reine la anarquía. Por el contrario, en muchos casos el Estado hace uso de instituciones basadas en usos y costumbres tradicionales, que dan cuenta del poder de las estructuras sociales pre-coloniales. Los clanes, las tribus, la familia extendida y las comunidades de aldeas y la autoridad tradicional que tienen como correlato, es decir los ancianos y los jefes de aldea determinan la realidad social y cotidiana de una parte considerable de la población, particularmente en zonas rurales y periféricas (Boege, Brown, Clements \& Nolan, 2008).

En este contexto, el reconocimiento de los líderes tradicionales busca confirmar la autoridad del Estado y da lugar al surgimiento de regímenes híbridos que funcionan generando un orden, pero que desde la perspectiva del Estado-Nación moderno no hacen más que debilitar la estructura estatal. El problema central que presenta este tipo de ordenamiento es que las fronteras estatales no suelen coincidir con las fronteras de las aldeas, tribus o clanes y la idea de nación excede a estas organizaciones locales, aglutinando a varias de ellas.

\section{Algunos casos de naciones fallidas}

\section{Iraq}

El caso iraquí es arquetípico en varios sentidos. Siendo una de las regiones de mayor antigüedad en la historia humana, su población vivió bajo distintos dominios hasta que, con la expansión musulmana bajo los otomanos, quedó en lo que fue ese imperio hasta su dislocamiento definitivo al concluir la primera guerra mundial. Quedó entonces como un protectorado británico, concedido por la recién fundada Sociedad de las Naciones, y éstos, deseosos de mantener la tensión entre los pueblos de la región, diagramaron Iraq conteniendo tres poblaciones diferenciadas: árabes sunitas, árabes chiíes y kurdos, además de otras minorías (turcomanos, armenios, circacianos, yezidíes, entre otros).

Cont. nota 5

la identificación nacional era... fuertemente lingüística, aun cuando en ninguno de ellos la lengua nacional era hablada para fines cotidianos por más que una pequeña minoría -se ha calculado que en Italia era el 2,5 por 100 en el momento de la unificación-, mientras que el resto hablaba varios idiomas que solían ser mutuamente incomprensibles. (Hobsbawm 2012, p. 47) 
Esta unidad, surgida entre 1920 y 1923, se mantuvo hasta 1958 bajo la monarquía hachemí, en que tras un nuevo golpe de Estado se proclamó la República. Poco antes de morir, el rey Faysal I admitía que:

no existe en absoluto [un] pueblo iraquí sino masas de seres humanos desprovistos de toda concepción patriótica, imbuidos en tradiciones religiosas... sin lazos sociales entre ellos... dados a la anarquía y perpetuamente dispuestos a levantarse contra cualquier forma de gobierno. (Citado por Martín Muñoz 2003, pp. 28-29)

El advenimiento de la república abrió el espacio para la lucha de poder que concluyó con el golpe de Estado de julio de 1968 con el control del Estado por parte del Baas, el que se mantendrá en el poder hasta el final de la era de Sadam Husein en 2003.

A partir de ese momento, de manera creciente, al desaparecer el aparato represivo que mantenía esa unidad política, comenzó un proceso de disgregación que se acentuó tras la retirada de las tropas ocupantes de la coalición -retirada en gran medida motivada por el fracaso de la reconstrucción políticamente viable del país- y las tres principales fracciones de la población se desarticularon entre sí: chiíes y sunitas se enfrascaron en una lucha mutua, mientras los kurdos fueron ganando creciente autonomía, comenzando una existencia relativamente independiente. Frente al gobierno chií, una parte significativa de los cuadros militares sunitas se incorporaron al Estado Islámico (ISIS), formando en los hechos un cuasiEstado con control territorial en el centro-noroeste iraquí y el norte sirio. La intervención de fuerzas occidentales inventó el Estado iraquí y, ocho décadas después, la intervención occidental provocó su colapso.

\section{Somalia}

El caso somalí tiene la particularidad de que la región es habitada ancestralmente por grupos nómades organizados en lo que se denomina "linaje segmentario", en el cual "la identidad y lealtad políticas se determinan por la proximidad o lejanía genealógica entro del sistema de clanes" (Ruiz-Giménez, 2003, p. 62). El desembarco británico en el cuerno de África hacia 1839-40, que desembocó en la creación de un Protectorado en 1886, no diluyó este sistema político, sino que superpuso otro tipo de organización. Algo similar ocurrió en el sur de esta región, ocupada por Italia, ocupada también desde fines del siglo XIX. En la zona norte la ocupación fue francesa (en lo que hoy es Djibouti) y en el oeste, en el Ogaden, fueron los etíopes quienes tomaron el control político.

Esta duplicidad en la organización política se mantuvo, aunque generando transformación en el sistema clánico, debido a la cooptación por parte de las potencias ocupantes de algunos jefes de clanes, quienes tenían acceso diferencial a los recursos, alterando las relaciones relativamente igualitarias inter-clánicas, que se regulaban por asambleas (shir) en las que se acordaba el uso de pasturas, del agua y de las rutas comerciales. Estos acuerdos eran 
inestables, y de manera recurrente se volvían a trazar alianzas en nuevas asambleas. Pero este sistema estaba ya alterado cuando, en el marco del proceso descolonizador ocurrido tras la Segunda Guerra Mundial, Somalia obtuvo su independencia en 1960, con los territorios hasta entonces controlados por italianos y británicos, es decir, dejando por fuera del nuevo territorio a población que pertenecía a las mismas tradiciones. Esta situación explica el apoyo del recién creado Estado somalí a los movimientos separatistas somalíes del norte de Kenia y del Ogadén etíope. El golpe de Estado de 1969 implantó un régimen pro-soviético (Syad Barre) que, con una retórica modernista (y con la ayuda soviética que le permite modernizar el ejército y la infraestructura del país), reforzó el papel de los clanes, al instaurarse el clan klatura en el aparato estatal.

La guerra por el Ogadén (1977-1978) cambió el alineamiento internacional de Somalia, dejando de estar bajo la influencia soviética para pasar a la órbita estadounidense -la URSS, hasta entonces aliada a Somalia tanto como a Etiopía, da un decisivo apoyo logístico a esta última, que determina el resultado de la guerra- (Soria 1986). Barre, con la ayuda ahora de Estados Unidos, refuerza la represión interna y la estructura clánica de control del aparato de Estado, en una situación de fuerte crisis económica provocada por sequías y el descenso de las exportaciones de ganado. Esto impulsa a la organización de una resistencia armada, que da origen a la guerra civil -en 1979 se organiza el Frente Democrático de Salvación Somalí, que actúa desde Etiopía, y en 1981 el Movimiento Nacional Somalí-. Barre firmó un acuerdo de no agresión con Etiopía, lo que le quitó legitimidad dentro de su estructura clánica. El fin de la Guerra Fría implicó la pérdida de interés geopolítico de las potencias mundiales en el "Cuerno de África" y, con ello, la antesala del colapso estatal. En enero de 1991 Barre abandona Mogadiscio, creándose un vacío de poder que llevó a la disolución fáctica del Estado.

Desde entonces la fragmentación política se estructura en base, ya no sólo a los clanes, sino a los señores de la guerra emergentes. En este clima de disgregación, dos territorios se consolidaron políticamente $y$, aunque carecían de reconocimiento internacional, cumplían con casi todos los requisitos de un Estado: Somaliland y Puntland, ambos en la parte norte. En Mogadiscio, en 2006 se estableció la Unión de Tribunales Islámicos, generando cierto orden $^{6}$, pero Etiopía, con el visto bueno estadounidense desbarató la experiencia. Pese a la homogeneidad étnica y religiosa, la preeminencia de la estructura de clanes impidió la formación de una nación en el sentido moderno del término. El Estado somalí solo funcionó tres décadas, aunque aún exista nominalmente.

6. Los Tribunales comenzaron a desmantelar el demencial laberinto de puestos de control y barreras que separaban el reino de un señor de la guerra del de su vecino, lo que repercutió en una bajada significativa del precio de los alimentos. Reabrieron los puertos y el aeropuerto al tráfico general, lo que facilitó un aumento espectacular del volumen de la ayuda humanitaria que llegaba realmente a Mogadiscio. Los índices de robos y otros delitos cayeron sustancialmente, y muchos habitantes locales comentaban a los periodistas que se sentían más seguros que nunca antes en dieciséis años. (Scahill, 2013, p. 277) 


\section{Afganistán}

Es diferente a los vistos. Compone una gran diversidad étnica, religiosa y lingüística. La mayor de las minorías es la pastún, con alrededor del $40 \%$ de la población, seguida por los tayikos, hazaras, uzbekos y, en menor medida, turkmenos y aimakos. Aunque el islam es la religión mayoritaria, hay fuertes influencias budistas y de zoroastrismo. Tiene dos lenguas oficiales (pastún y persa) pero se hablan diferentes dialectos. Históricamente fue una región de tránsito entre Oriente Medio (Persia), China y la India, aunque también limita con las poblaciones centroasiáticas. Las poblaciones tienen una ancestral organización tribal, desempeñándose como pequeños agricultores, crianza de ganado, mercaderes.

La historia del Estado afgano se remonta al siglo XIX y a la pugna geopolítica entre Gran Bretaña y Rusia, potencias que se disputaban el control de Asia (Fieldhouse 2006). En ese marco se instaló la dinastía Mohammadzai (1838-1973) contra la que los británicos libraron dos guerras (183942 y 1878-80), sin lograr imponerse dada la característica descentralizada de su organización política. Esta dinastía, cuyo poder interno efectivo fue siempre muy limitado, y tal vez su mayor virtud fue no entrometerse en demasía con la población, fue derrocada en 1973, cuando se fundó la República de Afganistán liderada por Mohammed Daud Kahn, quien a su vez fue derrocado en 1978 por el Partido Comunista, el que rápidamente solicitó asistencia en el terreno a la Unión Soviética, país que envió tropas y equipos en 1979. Es conocida la suerte del Ejército Rojo en esa región, empantanado ante una guerrilla apoyada por la CIA, que culminó con la retirada total en febrero de 1989. El gobierno formal afgano comenzó una debacle cuyo desenlace ocurrió en 1992, con la toma del poder por los talibán.

Sin embargo, nada de esto registra el hecho de que, como lúcidamente lo describiese Preston (2006, julio 10), Kabul es ante todo "una antigua ciudad-Estado, inconexa con el campo imperturbable, y que la ruralidad en el sudeste se extiende sin fronteras físicas en los páramos de Baluchistán, donde la autoridad del propio Pakistán apenas funciona". Es que el sistema tribal apenas tolera la existencia de un Estado central, siempre visto como un agente externo de perturbación ${ }^{7}$. Es justamente este sistema de lealtades, y de alianzas inestables, lo que explica el fracaso de los diversos intentos de estabilización de un Estado central y, en consecuencia, de dominación política del territorio interno por ninguna fuerza (sea afgana o de ocupación). La reluctancia cultural ancestral a tales intentos es la clave para entender la razón por la que han fracasado en los intentos de subyugar militarmente a una población que en su mayoría vive miserablemente las principales potencias de cada época (Gran Bretaña en el siglo XIX, la URSS en el XX, y Estados Unidos más aliados en el XXI).

7. "Cualquiera que esté vagamente familiarizado con la historia afgana sabe que la principal lealtad afgana va a la familia, al clan y a la tribu y que el gobierno central siempre ha sido visto, con razón, como una interferencia negativa" (Herold, 2007, pp. 123-124). 


\section{CONCLUSIONES}

Si entendemos por "nación" al lazo identitario y de pertenencia primordial en una comunidad política, en los casos mencionados queda expuesto el fracaso en su constitución. Y dicho fracaso es lo que le quita viabilidad al sostenimiento de un Estado en el tiempo.

Por ello, en los casos en que no logró conformarse el mito nacional, o éste fue demasiado débil -es decir, que generaron un lazo de menor fuerza que otras redes identitarias-, el Estado sólo puede sostenerse haciendo uso de la fuerza más o menos abierta y manifiesta. Pero, como lo señalaba van Loon, "con las bayonetas puede hacerse de todo, menos sentarse sobre ellas". El poder que no logra invisibilizarse en no mucho tiempo se resquebraja inevitablemente.

Esta necesidad fue la que dinamizó la conformación mítica de "naciones", proceso que, con sus particularidades y dificultades, tuvo cierto éxito en algunas regiones del mundo. Pero nada habilita a pensar que es una fórmula con validez universal.

Hemos expuesto tres casos en los que lo que tal intento ha abortado por defectos de origen y que, con alta probabilidad, en las mismas -y tal vez también en otras-, por sus peculiaridades sea inviable tal mito. Pero eso no significa que no se pueda pensar en términos de organización estatal. Como sugieren Boege, Brown, Clements \& Nolan "se debería intentar aprehender el contexto de lo que verdaderamente constituye el orden político en aquellas regiones de aparente fragilidad" (2008, p. 11).

Para comenzar tal ejercicio, deberíamos renunciar al uso del término "Estado fallido", reconociendo que se trata de un modelo, el de Estado-nación, que no logra viabilidad en algunas regiones, y que la falla no indica la imposibilidad de organización política estable, sino la de establecer una nación, que es una condición para subsanar una necesidad histórica en Europa, y que dicho modelo ha podido replicarse en algunos sitios, pero no en todos. En este sentido, quizás sea necesario pensar un orden que contemple la existente multinacionalidad de la mayor parte de los Estados que conocemos ${ }^{8}$.

El mito de la nación, como creador de lazos de solidaridad, en muchos casos deberá ser reemplazado por algún otro elemento aglutinador que recupere formas identitarias y formas organizativas preexistentes, dando lugar, a partir de la construcción de símbolos comunes, a nuevas formas estatales que posibiliten la construcción de una sociedad diversa.

8. En tal sentido no podemos dejar de mencionar el caso precursor del Estado plurinacional de Bolivia (que no es el único en el mundo, pero sí en nuestra región). 


\section{REFERENCIAS}

Alda, S. (2015). La debilidad del Imperio de la Ley en América Latina: un factor para entender la implantación del crimen organizado. Revista Española de Ciencia Política. 37. 63-88.

Alfonso, M. (2003). Los Estados Fallidos. Cuadernos de Estrategia. "Nuevos Riesgos para la sociedad del futuro". 120. Instituto Español de Estudios Estratégicos, Ministerio de Defensa, Madrid.

Bandieri, L. (2007) Introducción. En: Schmitt, C. Clausewitz como pensador político / El orden del mundo después de la Segunda Guerra Mundial (la Guerra Fría). Buenos Aires. Struhart \& Cía.

Boege, V.; Brown, A.; Clements, K. \& Nolan, A. (2008) ¿Qué es lo "Fallido"? ¿Los Estados del Sur, o la investigación y las políticas de occidente? Un estudio sobre órdenes políticos híbridos y los Estados emergentes. Madrid: Instituto Complutense de Estudios Internacionales.

Calatrava, A. \& Durán, M. (2011). La compleja Construcción del Estado en el Siglo XXI: el caso de los Estados Fallidos. En: Vázquez, R. (Coord.) Teorías actuales sobre el Estado Contemporáneo, (pp. 143-165). Granada: Universidad de Granada.

Crocker, C. (2003). Hitting the right targets. Foreign Affairs.

Fieldhouse, D. (2006). Los imperios coloniales desde el siglo XVIII. México DF: Siglo XXI.

Gellner, E. (1991). Naciones y nacionalismo. Buenos Aires: Editorial Alianza.

Gutiérrez, F. (2010). ¿Estados fallidos o conceptos fallidos? La clasificación de las fallas estatales y sus problemas. Revista de Estudios Sociales. 37. 87-104.

Herold, M. (2007). Afganistán como un espacio vacío. El perfecto Estado neocolonial del siglo XXI. Madrid: Editorial Foca.

Hobsbawm, E. (2012). Naciones y nacionalismo desde 1870. Barcelona: Crítica.

Martín, G. (2003). Iraq. Un fracaso de Occidente (1920-2003). Barcelona. Tusquets.

Oszlak, Ó. (1982). Reflexiones sobre la formación del Estado y la construcción de la sociedad argentina. Desarrollo Económico Revista de Ciencias Sociales. 31. 1-18.

Preston, P. (2006, julio 10). An imploding dust bowl, The Guardian, Recuperado de http://www. theguardian.com/commentisfree/2006/jul/10/comment.politics1 
Rice, S. \& Patrick, S. (2008). Index of State weakness in the developing world. Washington DC: The brookings institution.

Rosdolsky, R. (1980). Friedrich Engels y el problema de los pueblos "sin historia". México DF: Siglo XXI

Rotberg, R. (2002). Failed States in a World of Terror. Foreign Affairs.

Ruiz-Giménez, I. (2003). Las "buenas intenciones". Intervención humanitaria en África. Barcelona: Icaria.

Scahill, J. (2013). Guerras sucias. El mundo es un campo de batalla. Barcelona: Paidós.

Skinner, Q. (2003). El nacimiento del Estado. Buenos Aires: Gorla.

Soria, D. (1986). La guerra del Ogadén. Buenos Aires: Círculo Militar.

Waldmann, P. (2003). El Estado Anómico. Derecho, seguridad pública y vida cotidiana en América Latina. Madrid, Frankfurt: Iberoamericana.

Woodward, S. (2006). Fragile States: Exploring the concept. Madrid: FRIDE.

Zapata, J. (2014). La teoría del Estado Fallido: entre aproximaciones y disensos. Revista de Relaciones Internacionales, Estrategia y Seguridad. 9(1). 87-100. 